\title{
Association between excessive chronic iodine exposure and the occurrence of papillary thyroid carcinoma
}

\author{
FENGYAN HUANG $^{1}$, WEI CONG ${ }^{2}$, JUAN XIAO ${ }^{2}$, YONG ZHOU $^{2}$, MAOSONG GONG $^{2}$, JINGFU SUN ${ }^{2}$, \\ LIQUN SHAN $^{2}$, QIANG XIAO ${ }^{1}$, LIHUA WANG ${ }^{1}$, JIANING LIU ${ }^{2}$, ZHIGANG YU ${ }^{2}$ and HONGYING JIA ${ }^{1,2}$ \\ ${ }^{1}$ Department of Epidemiology and Health Statistics, School of Public Health, Cheeloo College of Medicine, \\ Shandong University, Jinan, Shandong 250012; ${ }^{2}$ Department of Thyroid Surgery, The Second Hospital, \\ Cheeloo College of Medicine, Shandong University, Jinan, Shandong 250033, P.R. China
}

Received March 9, 2020; Accepted August 4, 2020

DOI: $10.3892 / 01.2020 .12051$

\begin{abstract}
The aim of the present study was to elucidate the association between excessive chronic iodine exposure and the risk of developing papillary thyroid carcinoma (PTC). The demographic information and pathological characteristics of patients with thyroid nodules were retrieved from medical records at The Second Hospital of Shandong University. A fasting urine specimen was collected, and creatinine and urinary iodine concentration (UIC) were determined. The water iodine data from the domicile districts of these patients were collated from published reports. The results revealed that almost half of the patients with PTC (44.3\%) also exhibited a high UIC ( $\geq 300 \mu \mathrm{g} / \mathrm{l})$. Multivariate analysis revealed that the adjusted odds ratio for high UIC was 3.987 (95\% CI: $1.355-11.736)$ and the adjusted area under the receiver operating characteristic curve was 0.776 (95\% CI: 0.687-0.864), which was associated with PTC risk in patients with thyroid nodules. Integrated ecological assessment of chronic iodine exposures demonstrated that $>80 \%(81.4 \%)$ of the patients with PTC who also exhibited a high UIC were from historically non-iodine-deficient regions, and $66.7 \%$ of patients with PTC who resided in historically iodine-excessive regions were characterized by high UICs. Importantly, a high UIC was significantly associated with capsular invasion and extrathyroid metastasis $(\mathrm{P}<0.05)$. Moreover, self-matching results
\end{abstract}

Correspondence to: Professor Jianing Liu, Department of Thyroid Surgery, The Second Hospital, Cheeloo College of Medicine, Shandong University, 247 Beiyuan Dajie Street, Jinan, Shandong 250033, P.R. China

E-mail: 15153169328@163.com

Professor Hongying Jia, Department of Epidemiology and Health Statistics, School of Public Health, Cheeloo College of Medicine, Shandong University, 44 Wenhua Xi Road, Jinan, Shandong 250012, P.R. China

E-mail: jiahongying@sdu.edu.cn

Key words: papillary thyroid carcinoma, urinary iodine concentration, water iodine, capsular invasion, extrathyroid metastases indicated that, in patients with PTC, there were no significant differences in UIC grading between the pre- and postoperative specimens. In conclusion, excessive chronic iodine exposure is significantly associated with the risk of PTC, which contributes to increased capsular invasion and extrathyroid metastases. However, further research is required to validate these findings and to elucidate the potential molecular mechanisms involved.

\section{Introduction}

The incidence of thyroid carcinoma (TC) has been increasing worldwide, with the papillary TC (PTC) histological subtype accounting for $84 \%$ of all cases $(1,2)$. Epidemiological studies suggest that, in $>40 \%$ of the cases, the causative factors of PTC were manageable, including exposure to radiation, obesity, cigarette smoking and unbalanced nutrition (3). However, the accurate identification of controllable risk factors for PTC remains incomplete.

Iodine is used in the metabolism of thyroid gland hormones. A number of epidemiological studies have attempted to elucidate the association between excessive iodine intake and the risk of developing PTC. For example, Lee et al (4) found that the median urinary iodine concentration (UIC) and food frequency questionnaire score in patients with PTC were significantly higher compared with those in healthy control subjects. Zhou et al (5) discovered that UIC was higher in patients with nodular goiter and PTC compared with the general population. Based on a pair-matching case-control study design, Zhang et al (6) demonstrated that UIC was associated with PTC risk. Zhao et al (7) indicated that a higher than average UIC was associated with an increased risk of larger tumors in female patients with PTC. Furthermore, Zhao et al (8) and Wang et al (9) observed that UIC was associated with lymph node metastasis in patients with PTC, and Kim et al (10) identified UIC as an independent predictor of BRAF mutations in PTC. However, the aforementioned results were obtained based on random UIC measurements, which only reflect iodine status at specific time points, and cannot be used to independently represent chronic iodine exposure. In TC ecology research, further studies evaluated iodine exposure according to the water iodine levels of the domicile districts of patients; however, this design lacks individual iodine 
exposure assessment (11-13). Furthermore, Santos et al (14) used reservoir water iodine content combined with UIC to evaluate chronic iodine exposure in thyroid histology pattern research. Zhang et al (15) investigated iodized salt consumption combined with UIC to estimate long-term iodine intake. However, this ecology-based integrated assessment design of iodine exposure (which utilized water iodine or iodized salt consumption combined with the UIC) is rarely applied for the analysis of clinicopathological characteristics in PTC.

In the present study, UIC was innovatively combined with water iodine values to determine the intrinsic association between iodine exposure and the clinical characteristics of PTC. Ecological integrated assessment was performed to determine whether there is an association of excessive chronic iodine exposure with capsular invasion and extrathyroid metastases. Further exploration of the controllable risk factors of PTC may provide novel insights and a reference for regional primary preventive strategies, and may aid the identification of biomarkers for the early diagnosis of PTC.

\section{Materials and methods}

Study population. The present study involved patients with thyroid nodules who underwent thyroidectomy at the Department of Thyroid Surgery, The Second Hospital of Shandong University (Jinan, China), between July 2019 and December 2019. The exclusion criteria were as follows: i) Patients with a family history of TC; ii) history of radiation exposure during childhood; iii) recent use of therapeutic iodine (2 months); iv) use of antithyroid drugs or thyroid hormone therapy; and v) patients with kidney or liver dysfunction, and/or other systemic diseases. The pathohistological type of the thyroid nodules was determined by a pathologist at the Department of Pathology. Finally, after excluding patients with medullary, follicular and undifferentiated TC, 151 patients with thyroid nodules remained, including 97 PTC and 54 non-PTC patients. The Research Ethics committee of The Second Hospital of Shandong University approved the present study and allowed oral consent to be obtained from patients [approval no. KYLL-2019(KJ)P-0084]. All the patients were informed of the purpose of the study and volunteered to participate in this research by oral consent.

Iodine exposure assessment. A fasting urine specimen was collected by clinical professionals between 6:00 and 7:00 a.m., and the UIC was determined using an iodine determination kit (cat. no. 160031; Xiangyang Wentes Health Technology Co., Ltd.) and a matching iodine detector instrument (OTT-I-P; Xiangyang Wentes Health Technology Co., Ltd.). During testing, the experimental environment was kept free of iodine, and the external and internal quality controls were processed according to the standard protocols of The Second Hospital of Shandong University. The reference materials were certified lyophilized human reference urine iodine (GBW09108-GBW09110) produced by the National Reference Laboratory for Iodine Deficiency Disorders. The urinary creatinine concentration was determined using the Analyzer A25 (BioSystems S.A.). Both UIC and urinary creatinine were processed within $2 \mathrm{~h}$ after collection. According to the recommendations of the World Health Organization (16), the iodine nutritional status was categorized into three degrees as follows: i) Low UIC $(<100 \mu \mathrm{g} / \mathrm{l})$, iodine-deficient; ii) adaptive UIC (100-299 $\mu \mathrm{g} / \mathrm{l})$, iodine-adequate; and iii) high UIC $(\geq 300 \mu \mathrm{g} / \mathrm{l})$, iodine-excessive.

The environmental water iodine data for domicile districts of the Shandong province were consulted (17). According to the grading standard for water iodine (17), Shandong was divided into three groups as follows: i) Historically iodine-deficient regions (median water iodine levels $<10 \mu \mathrm{g} / \mathrm{l}$ ); ii) historically iodine-adaptive regions (median water iodine levels $10-150 \mu \mathrm{g} / \mathrm{l}$ ); and iii) historically iodine-excessive regions (median water iodine levels $>150 \mu \mathrm{g} / \mathrm{l}$ ).

Clinical characteristics. In line with previously published standards (18), patients with thyroid nodules were categorized into four groups according to Thyroid Imaging Reporting and Data System (TIRADS) grading as follows: Group 1, TIRADS 2 and 3; group 2, TIRADS 4a; group 3, TIRADS 4b; and group 4, TIRADS 4c and 5. Descriptions of nodule multifocality and bilaterality were obtained from ultrasound reports. For cases with multiple reports, the latest ultrasound report and the highest TIRADS grade were selected.

Diagnoses were reached using surgical slides from the Department of Pathology, and the histological type of TC was determined. Characteristics including primary tumor size, location, capsular invasion, extrathyroid metastasis and lymph node status were evaluated based on the National Comprehensive Carcinoma Network guidelines (version 2; 2014) for TC recommendations (https://www.nccn.org). Primary and secondary pathological changes were examined and described in detail in the associated pathological reports. The comprehensive assessment of PTC was performed by the Departments of Thyroid Surgery and Pathology, and the demographic and pathological characteristics of each patient were obtained from medical records.

Statistical analysis. All data were entered by two researchers and cross-checked using EpiData 3.0 software (https://www. epidata.dk) for quality control. Descriptive analyses of basic characteristics are presented either as the mean \pm standard deviation or as percentages. $\chi^{2}$, Student's t-test and F-test, and one-way ANOVA (with Bonferroni's test for multiple comparisons) were used for comparative analysis. McNemar's test was used for self-matching comparative analyses. Univariate and multivariate logistic regression analyses were performed using SPSS software, version 22.0 (IBM Corp.). Collinearity diagnostics results indicated that there was no multicollinearity for each variable in multiple conditional logistic regression models. A receiver operating characteristic (ROC) curve was generated using R software, version 3.5.1 (https://www.r-project.org), and Sigma Plot, version 14.0 (Systat Software, Inc.) and R were used for data presentation. $\mathrm{P}<0.05$ was considered to indicate a statistically significant difference.

\section{Results}

Association between UIC and PTC risk in patients with thyroid nodules. Basic characteristics. The data of 151 patients with thyroid nodules were analyzed. The patients included 41 men and 110 women, and their mean age \pm SD was $49.2 \pm 13.0$ years 
Table I. Basic characteristics of PTC and non-PTC among patients with thyroid nodules.

\begin{tabular}{|c|c|c|c|c|}
\hline Characteristic & PTC (n=97) & Non-PTC $(\mathrm{n}=54)$ & $\mathrm{t} / \chi^{2}$ value & P-value \\
\hline $\mathrm{Age}^{\mathrm{a}}$, years & $45.5 \pm 12.5$ & $55.9 \pm 11.2$ & -5.065 & $<0.001$ \\
\hline \multicolumn{5}{|l|}{$\operatorname{Sex}^{b}$} \\
\hline Female & $73(75.3)$ & $37(68.5)$ & 0.796 & 0.372 \\
\hline Male & $24(24.7)$ & $17(31.5)$ & & \\
\hline \multicolumn{5}{|l|}{ Smoking habit ${ }^{\mathrm{b}}$} \\
\hline Smoker & $9(9.3)$ & $6(11.1)$ & 0.130 & 0.718 \\
\hline Non-smoker & $88(90.7)$ & $48(88.9)$ & & \\
\hline \multicolumn{5}{|l|}{$\mathrm{BMI}^{\mathrm{b}}, \mathrm{kg} / \mathrm{m}^{2}$} \\
\hline$<24.0$ & $47(48.5)$ & $31(57.4)$ & 1.114 & 0.291 \\
\hline$\geq 24.0$ & $50(51.5)$ & $23(42.6)$ & & \\
\hline \multicolumn{5}{|l|}{ Blood pressure $^{\mathrm{a}}, \mathrm{mm} / \mathrm{Hg}$} \\
\hline Systolic & $78.4 \pm 8.4$ & $81.1 \pm 9.7$ & -1.514 & 0.132 \\
\hline Diastolic & $129.3 \pm 10.6$ & $133.3 \pm 11.9$ & -1.732 & 0.086 \\
\hline \multicolumn{5}{|l|}{ TIRADS grade ${ }^{b}$} \\
\hline$\geq 4 \mathrm{c}$ & $44(45.4)$ & $5(9.2)$ & 73.922 & $<0.001$ \\
\hline $4 b$ & $26(26.8)$ & $3(5.6)$ & & \\
\hline $4 a$ & $21(21.6)$ & $9(16.7)$ & & \\
\hline$\leq 3$ & $6(6.2)$ & $37(68.5)$ & & \\
\hline \multicolumn{5}{|l|}{ Multifocality ${ }^{\mathrm{b}}$} \\
\hline Yes & $44(45.4)$ & $40(74.1)$ & 11.587 & 0.001 \\
\hline No & $53(54.6)$ & $14(25.9)$ & & \\
\hline \multicolumn{5}{|l|}{ Location $^{b}$} \\
\hline Bilateral & $37(38.1)$ & $20(37.0)$ & 0.018 & 0.893 \\
\hline Unilateral & $60(61.9)$ & $34(63.0)$ & & \\
\hline \multicolumn{5}{|l|}{$\mathrm{UIC}^{\mathrm{b}}, \mu \mathrm{g} / 1$} \\
\hline$<100$ & $16(16.5)$ & $12(22.2)$ & 7.335 & 0.026 \\
\hline $100-299$ & $38(39.2)$ & $30(55.6)$ & & \\
\hline$\geq 300$ & $43(44.3)$ & $12(22.2)$ & & \\
\hline Urinary creatinine $^{\mathrm{a}}, \mu \mathrm{mol} / \mathrm{l}$ & $109.0 \pm 79.4$ & $111.9 \pm 63.6$ & -0.228 & 0.820 \\
\hline \multicolumn{5}{|l|}{ 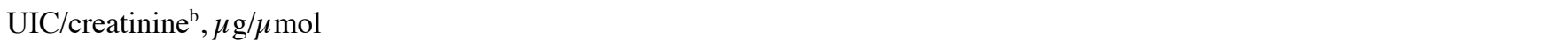 } \\
\hline$<2.0$ & $32(33.0)$ & $23(42.6)$ & 2.584 & 0.275 \\
\hline $2.0-9.9$ & $43(44.3)$ & $24(44.4)$ & & \\
\hline$\geq 10.0$ & $22(22.7)$ & $7(13.0)$ & & \\
\hline
\end{tabular}

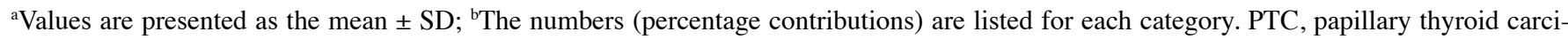
noma; BMI, body mass index; TIRADS, Thyroid Imaging Reporting and Data System; UIC, urinary iodine concentration.

(age range, 17-75 years). The comparison of basic characteristics, including general demographic information, nodule ultrasound data and UIC, between PTC and non-PTC patients is displayed in Table I and Fig. 1. Not a few PTC patients $(32.0 \%)$ were located in 30-40 years group, far more than that in non-PTC patients (9.3\%); by contrast, few PTC patients $(10.3 \%)$ were aged over 60 years, far less than that in non-PTC patients (37.0\%) (Fig. 1A). Almost half (45.4\%) of PTC patients manifested as multifocality of nodules, significantly lower than that in non-PTC patients with $74.1 \%$ (Fig. 1B). Approximately half of the PTC patients (44.3\%) exhibited a high UIC $(\geq 300 \mu \mathrm{g} / \mathrm{l})$, which was significantly higher compared with that of the non-PTC patients $(22.2 \%)$; by contrast, the proportion of PTC patients with adaptive UICs $(100-299 \mu \mathrm{g} / \mathrm{l})$ was $39.2 \%$, which was markedly lower compared with that of the non-PTC patients (55.6\%) (Fig. 1C). No significantly difference was showed between PTC and non-PTC patients for UIC/creatinine (Fig. 1D).

Logistic regression analysis. A lower age [univariate analysis: Odds ratio $(\mathrm{OR})=5.186$; 95\% CI: 2.217-12.134; multivariate analysis: $\mathrm{OR}=5.192$; 95\% CI: 2.215-12.171 (both $\mathrm{P}<0.001$ )], multifocality of nodules [univariate analysis: $\mathrm{OR}=0.291$; 95\% CI: 0.140-0.602 ( $\mathrm{P}=0.001)$; multivariate analysis: $\mathrm{OR}=0.334 ; 95 \% \mathrm{CI}: 0.154-0.724(\mathrm{P}=0.005)]$, and high UIC [univariate analysis: $\mathrm{OR}=3.359 ; 95 \% \mathrm{CI}$ : 1.297-8.701 ( $\mathrm{P}=0.013)$; 

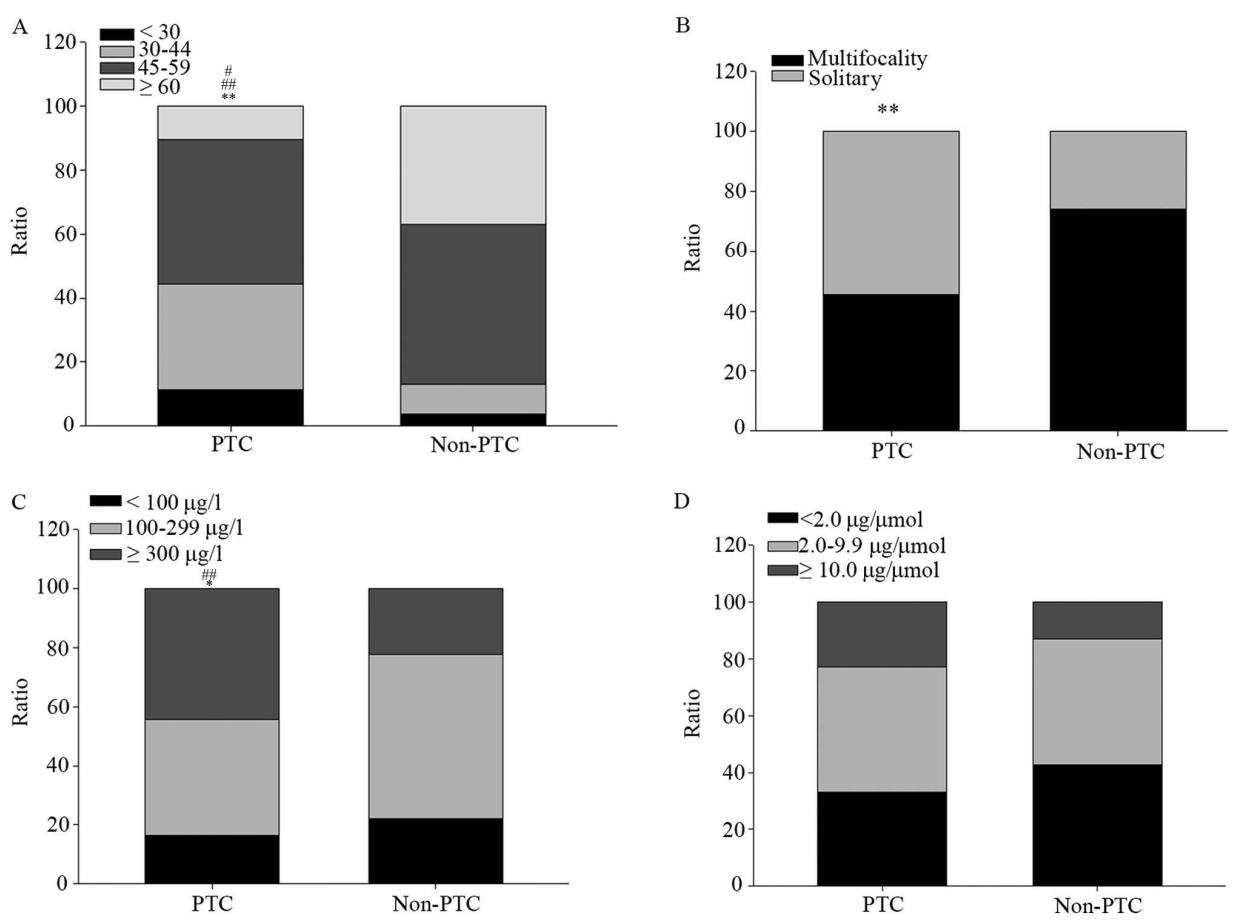

Figure 1. Distribution of basic characteristics between PTC and non-PTC among patients with thyroid nodules. (A) Age distribution. ${ }^{\text {"P }}<0.05$ vs. non-PTC group for $<30$ age range. ${ }^{\# \#} \mathrm{P}<0.01$ vs. non-PTC group for $\geq 60$ age range. (B) Multifocality of nodule distribution. (C) UIC distribution. ${ }^{\# \#} \mathrm{P}<0.01$ vs. non-PTC group for $\geq 300 \mu \mathrm{g} / \mathrm{l}$. (D) UIC/creatinine distribution. " $\mathrm{P}<0.05$ and ${ }^{* * *} \mathrm{P}<0.01$ vs. non-PTC group. PTC, papillary thyroid carcinoma; UIC, urinary iodine concentration.

multivariate analysis: $\mathrm{OR}=3.987 ; 95 \% \mathrm{CI}: 1.355-11.736$ $(\mathrm{P}=0.012)]$ were identified as predictors of PTC risk in patients with thyroid nodules (Table II).

Diagnostic value analysis. The area under the ROC curve (95\% CI), cut-off value, sensitivity and specificity were 0.681 (0.581-0.782), $399.0 \mu \mathrm{g} / \mathrm{l}$ (UIC) $(0.432,0.857)$ for univariate analysis, and $0.776(0.687-0.864), 0.353$ (prediction probability) $\mu \mathrm{g} / \mathrm{l}(0.679,0.762)$ for multivariate analysis, after adjusting potential covariates, such as sex, age, smoking habits and body mass index (BMI) (Fig. 2).

Analysis of UIC and clinicopathological characteristics. Compared with a low UIC, adaptive and high UICs were both significantly associated with capsular invasion of PTC $(\mathrm{P}<0.05)$. Compared with an adaptive UIC, only a high UIC was significantly associated with extrathyroid metastasis $(\mathrm{P}<0.05)$. No notable association was observed between UIC and age, sex, smoking habits, BMI, tumor size, complications or lymph node status in patients with PTC (Table III).

Assessment of excessive chronic iodine exposure. The water iodine data of the domicile districts of patients with PTC were utilized and combined with the UIC to conduct ecology integrated assessment of chronic iodine exposure. Among patients with PTC who exhibited high UICs, $81.4 \%$ were from historically non-iodine deficient regions (Table III). Among those residing in historically iodine-excessive regions, $66.7 \%$ exhibited a high UIC, whereas only $7.4 \%$ had low UIC values (Table IV). An association between high UIC and historically iodine-excessive regions was also noted. Thus, in the present study, high UIC was found to independently reflect excessive chronic iodine exposure in patients with PTC.
Pre- and postoperative alterations in UIC in patients with PTC. There were no significant changes in the UIC grading between pre- and postoperative samples $(\mathrm{P}>0.05$; Table V and Fig. S1) in patients with PTC. Among patients with a high preoperative UIC, $90.0 \%$ also exhibited a high postoperative UIC, regardless of the presence of carcinomatous foci. These findings indicated that a high UIC did not result from the metabolic properties of the PTC per se.

\section{Discussion}

The association between iodine intake and thyroid diseases has been suggested to follow a U-shaped distribution $(19,20)$. However, few studies have determined the specific role of chronic excessive iodine exposure in the development of PTC. The results of the present study suggested that almost half of the patients with PTC (44.3\%) exhibited a high UIC $(\geq 300 \mu \mathrm{g} / \mathrm{l})$, and that the proportion of patients with PTC with a high UIC was significantly higher compared with that observed in those without PTC (44.3 vs. $22.2 \%$, respectively). Together with the results of logistic regression and ROC curve analysis, it was comprehensively hypothesized that a high UIC may serve as a predictor or biomarker for PTC risk in patients with thyroid nodules. This hypothesis is supported by other similar studies, although there was no sufficient evidence to identify excessive iodine as an independent predictor of PTC (4-12). The UIC is also a widely accepted indicator of iodine nutritional status (which is almost entirely dependent on iodine exposure, including dietary intake) owing to the fact that $>90 \%$ of ingested iodine is excreted in the urine. Therefore, it was further proposed that excessive iodine exposure was significantly associated with the risk of PTC. 
Table II. Logistic regression analysis for predictors of papillary thyroid carcinoma risk in patients with thyroid nodules.

\begin{tabular}{|c|c|c|c|c|c|c|}
\hline \multirow[b]{2}{*}{ Characteristic } & \multicolumn{3}{|c|}{ Univariate analysis } & \multicolumn{3}{|c|}{ Multivariate analysis $^{\mathrm{a}}$} \\
\hline & OR & $95 \% \mathrm{CI}$ & P-value & OR & $95 \%$ CI & P-value \\
\hline \multicolumn{7}{|l|}{ Sex } \\
\hline Female & 1.00 & & & 1.00 & & \\
\hline Male & 1.398 & $0.669-2.919$ & 0.373 & 1.405 & $0.643-3.071$ & 0.394 \\
\hline \multicolumn{7}{|l|}{ Age, years } \\
\hline$>45$ & 1.00 & & & 1.00 & & \\
\hline$\leq 45$ & 5.186 & $2.217-12.134$ & $<0.001$ & 5.192 & $2.215-12.171$ & $<0.001$ \\
\hline \multicolumn{7}{|l|}{ Smoking habit } \\
\hline Smoker & 1.00 & & & 1.00 & & \\
\hline Non-smoker & 0.604 & $0.206-1.767$ & 0.357 & 0.848 & $0.248-2.892$ & 0.792 \\
\hline \multicolumn{7}{|l|}{ BMI, $\mathrm{kg} / \mathrm{m}^{2}$} \\
\hline$<4.0$ & 1.00 & & & 1.00 & & \\
\hline$\geq 24.0$ & 1.765 & $0.901-3.458$ & 0.098 & 1.914 & $0.959-3.821$ & 0.066 \\
\hline Multifocality & 0.291 & $0.140-0.602$ & 0.001 & 0.334 & $0.154-0.724$ & 0.005 \\
\hline Bilaterality & 0.774 & $0.388-1.541$ & 0.465 & 0.979 & $0.478-2.135$ & 1.010 \\
\hline \multicolumn{7}{|l|}{$\mathrm{UIC}, \mu \mathrm{g} / \mathrm{l}$} \\
\hline $100-299$ & 1.00 & & & 1.00 & & \\
\hline$<100$ & 2.546 & $1.135-5.712$ & 0.023 & 2.252 & $0.943-5.375$ & 0.067 \\
\hline$\geq 300$ & 3.359 & $1.297-8.701$ & 0.013 & 3.987 & $1.355-11.736$ & 0.012 \\
\hline \multicolumn{7}{|c|}{ UIC/creatinine, $\mu \mathrm{g} / \mu \mathrm{mol}$} \\
\hline $2.0-9.9$ & 1.00 & & & 1.00 & & \\
\hline$<2.0$ & 1.845 & $0.696-4.887$ & 0.218 & 2.107 & $0.722-6.148$ & 0.173 \\
\hline$\geq 10.0$ & 2.167 & $0.779-6.033$ & 0.139 & 2.516 & $0.822-7.698$ & 0.106 \\
\hline
\end{tabular}

${ }^{\text {a} A d j u s t e d ~ p o t e n t i a l ~ c o v a r i a t e s ~ s u c h ~ a s ~ s e x, ~ a g e, ~ s m o k i n g ~ h a b i t s ~ a n d ~ B M I . ~ O R, ~ o d d s ~ r a t i o ; ~ C I, ~ c o n f i d e n c e ~ i n t e r v a l ; ~ B M I, ~ b o d y ~ m a s s ~ i n d e x ; ~}$ UIC, urinary iodine concentration.
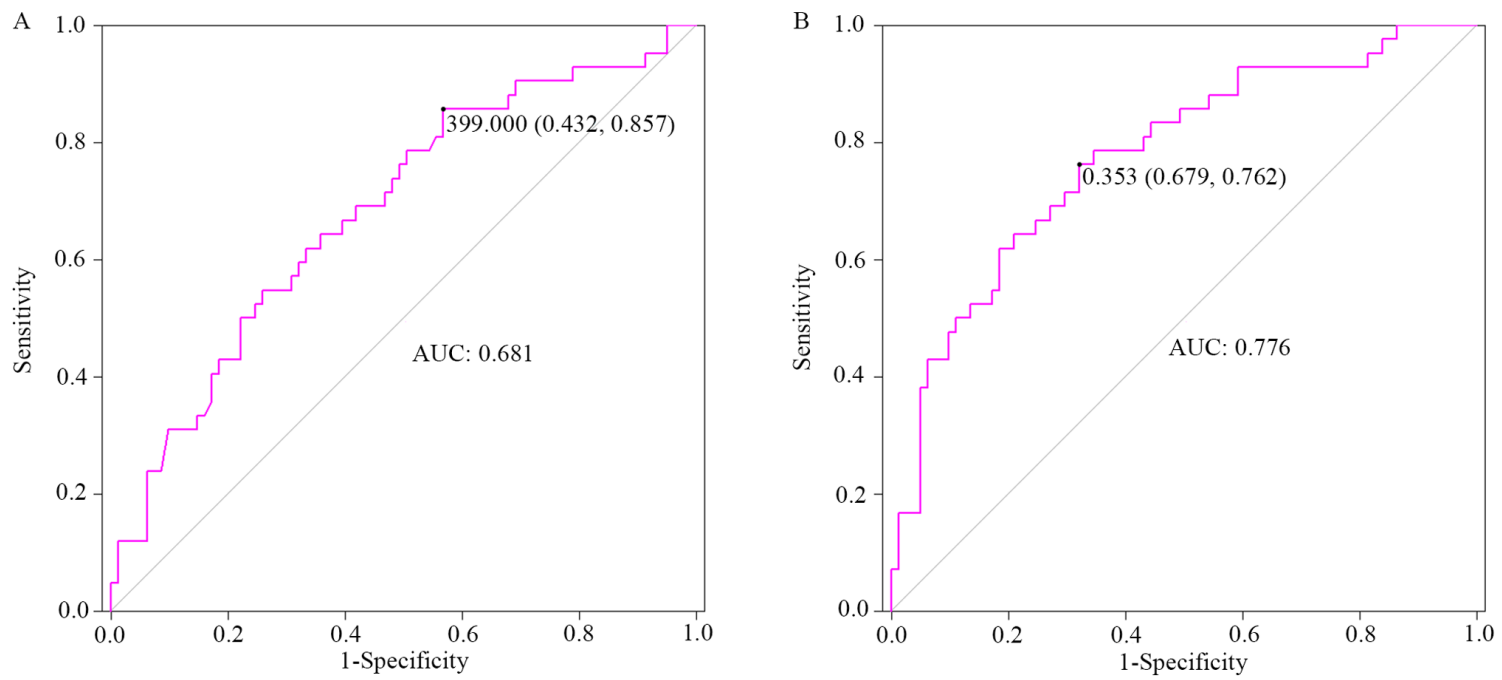

Figure 2. Diagnostic value of high urinary iodine concentration for papillary thyroid carcinoma risk in patients with thyroid nodules. (A) ROC curve by univariate analysis. (B) ROC curve by multivariate analysis following adjustment for potential covariates, including sex, age, smoking habits and body mass index. ROC, receiver operating characteristic; AUC, area under the ROC curve.

It is worth mentioning that the most innovative characteristic of present study is the fact that the UIC was combined with the water iodine levels of domicile districts, and that this integrated evaluation assessed chronic iodine exposure based on ecology. The data revealed that a substantial proportion of patients with PTC ( 70\%) who resided in historically iodine-excessive regions 
Table III. Association between UIC and clinicopathological characteristics among patients with papillary thyroid carcinoma.

\begin{tabular}{|c|c|c|c|c|c|}
\hline \multirow[b]{2}{*}{ Characteristic } & \multicolumn{4}{|c|}{$\mathrm{UIC}, \mu \mathrm{g} / \mathrm{l}$} & \multirow[b]{2}{*}{ P-value } \\
\hline & $<100$ & 100-299 & $\geq 300$ & $\mathrm{~F} / \chi^{2}$ value & \\
\hline Number $^{\mathrm{a}}$ & $16(16.5)$ & $38(39.2)$ & $43(44.3)$ & & \\
\hline $\mathrm{Age}^{\mathrm{b}}$, years & $46.3 \pm 15.1$ & $46.1 \pm 12.0$ & $44.6 \pm 12.2$ & 0.192 & 0.825 \\
\hline \multicolumn{6}{|l|}{$\operatorname{Sex}^{\mathrm{a}, \mathrm{c}}$} \\
\hline Female & $13(81.2)$ & $27(71.1)$ & $33(76.7)$ & 0.728 & 0.695 \\
\hline Male & $3(18.8)$ & $11(28.9)$ & $10(23.3)$ & & \\
\hline \multicolumn{6}{|l|}{ Smoking habit ${ }^{\mathrm{a}, \mathrm{c}}$} \\
\hline Smoker & $2(12.5)$ & $2(5.3)$ & $5(11.6)$ & 1.293 & 0.544 \\
\hline Non-smoker & $14(87.5)$ & $36(94.7)$ & $38(88.4)$ & & \\
\hline \multicolumn{6}{|l|}{$\mathrm{BMI}^{\mathrm{a}}, \mathrm{kg} / \mathrm{m}^{2}$} \\
\hline$<24.0$ & $8(50.0)$ & $17(44.7)$ & $22(51.2)$ & 0.352 & 0.839 \\
\hline$\geq 24.0$ & $8(50.0)$ & $21(55.3)$ & $21(48.8)$ & & \\
\hline \multicolumn{6}{|l|}{ Water iodine $\mathrm{a}^{\mathrm{a}, \mathrm{c}, \mathrm{d}}, \mu \mathrm{g} / \mathrm{l}$} \\
\hline$\geq 10.0$ & $6(37.5)$ & $16(42.1)$ & $35(81.4)$ & 17.787 & 0.001 \\
\hline $2-10$ & $8(50.0)$ & $15(39.5)$ & $6(13.9)$ & & \\
\hline$<2$ & $2(12.5)$ & $7(18.4)$ & $2(4.7)$ & & \\
\hline \multicolumn{6}{|l|}{ TIRADS grades ${ }^{\mathrm{a}, \mathrm{c}}$} \\
\hline$\geq 4 \mathrm{c}$ & $9(56.3)$ & $16(42.2)$ & $19(44.2)$ & 2.425 & 0.658 \\
\hline $4 \mathrm{~b}$ & $2(12.5)$ & $11(28.9)$ & $13(30.2)$ & & \\
\hline$\leq 4 \mathrm{a}$ & $5(31.2)$ & $11(28.9)$ & $11(25.6)$ & & \\
\hline \multicolumn{6}{|l|}{ Multifocality $^{\mathrm{a}}$} \\
\hline Yes & $5(31.3)$ & $23(60.5)$ & $16(37.2)$ & 5.964 & 0.051 \\
\hline No & $11(68.7)$ & $15(39.5)$ & $27(62.8)$ & & \\
\hline \multicolumn{6}{|l|}{ Primary tumor size ${ }^{\mathrm{a}}, \mathrm{cm}$} \\
\hline$>1.0$ & $6(38.5)$ & $12(26.7)$ & $17(36.6)$ & 0.570 & 0.752 \\
\hline$\leq 1.0$ & $10(61.5)$ & $26(73.3)$ & $26(63.4)$ & & \\
\hline \multicolumn{6}{|l|}{ Capsular invasion ${ }^{\mathrm{a}, \mathrm{e}}$} \\
\hline Invasion & $6(37.5)$ & $28(73.7)$ & $33(76.7)$ & 9.029 & 0.011 \\
\hline No invasion & $10(62.5)$ & $10(26.3)$ & $10(23.3)$ & & \\
\hline \multicolumn{6}{|l|}{ Location $^{\mathrm{a}, \mathrm{c}}$} \\
\hline Bilateral & $2(12.5)$ & $19(50.0)$ & $16(37.2)$ & 7.464 & 0.024 \\
\hline Unilateral & $14(87.5)$ & $19(50.0)$ & $27(62.8)$ & & \\
\hline \multicolumn{6}{|c|}{ Extrathyroid metastasis ${ }^{\mathrm{a}, \mathrm{d}}$} \\
\hline Yes & $10(62.5)$ & $16(42.1)$ & $30(69.8)$ & 6.504 & 0.039 \\
\hline No & $6(37.5)$ & $22(57.9)$ & $13(30.2)$ & & \\
\hline \multicolumn{6}{|l|}{ Complications $^{\mathrm{a}, \mathrm{c}}$} \\
\hline Yes & $12(75.0)$ & $21(55.3)$ & $27(62.8)$ & 1.947 & 0.378 \\
\hline No & $4(25.0)$ & $17(44.7)$ & $16(37.2)$ & & \\
\hline \multicolumn{6}{|l|}{ Lymph nodes ${ }^{\mathrm{a}, \mathrm{c}}$} \\
\hline Central district area & $13(81.3)$ & $30(78.9)$ & $34(79.1)$ & 0.042 & 0.979 \\
\hline Non-central area & $3(18.7)$ & $8(21.1)$ & $9(20.9)$ & & \\
\hline \multicolumn{6}{|l|}{ Central metastasis ${ }^{\mathrm{a}}$} \\
\hline Yes & $10(62.5)$ & $14(36.8)$ & $26(60.5)$ & 5.428 & 0.066 \\
\hline No & $6(37.5)$ & $24(63.2)$ & $17(39.5)$ & & \\
\hline
\end{tabular}

${ }^{a}$ The numbers (percentage contribution) are listed for each category. ${ }^{b}$ Values are displayed as the mean \pm SD. ${ }^{c}$ Correction for continuity. ${ }^{\mathrm{d} B o n f e r r o n i ' s ~ t e s t ~ s h o w s ~ s i g n i f i c a n t ~ d i f f e r e n c e s ~ b e t w e e n ~ t h e ~} \geq 300$ and the 100-299 $\mu \mathrm{g} / \mathrm{l}$ groups (following comparison of three groups using the $\chi^{2}$ or one-way ANOVA analysis); all $\mathrm{P}<0.05$. 'ंBonferroni's test shows significant differences between the $\geq 300$ and $<100 \mu \mathrm{g} / \mathrm{l}$ groups, and the 100-299 and $<100 \mu \mathrm{g} / 1$ groups; all $\mathrm{P}<0.05$. UIC, urinary iodine concentration; BMI, body mass index; TIRADS, Thyroid Imaging Reporting and Data System. 
Table IV. Assessment of UIC combined with water iodine in patients with papillary thyroid carcinoma.

\begin{tabular}{lccc}
\hline & \multicolumn{2}{c}{ Residence, region } \\
\cline { 2 - 4 } $\mathrm{UIC}^{\mathrm{a}}, \mu \mathrm{g} / 1$ & Iodine-deficient & Iodine-adaptive & Iodine-excessive \\
\hline$<100$ & $10(25.0)$ & $4(13.3)$ & $2(7.4)$ \\
$100-299$ & $22(55.0)$ & $9(30.0)$ & $7(25.9)$ \\
$\geq 300$ & $8(20.0)$ & $17(56.7)$ & $18(66.7)$ \\
Total & $40(100.0)$ & $30(100.0)$ & $27(100.0)$ \\
\hline
\end{tabular}

${ }^{a}$ The numbers (percentage contribution) are listed for each category. UIC, urinary iodine concentration.

Table V. Pre- and postoperative UIC in patients with papillary thyroid carcinoma.

\begin{tabular}{|c|c|c|c|c|}
\hline \multirow[b]{2}{*}{$\mathrm{UIC}^{\mathrm{a}}, \mu \mathrm{g} / 1$} & \multicolumn{2}{|c|}{ Postoperative } & \multirow[b]{2}{*}{ Total } & \multirow[b]{2}{*}{ P-value } \\
\hline & $<300$ & $\geq 300$ & & \\
\hline Preoperative & & & & $0.065^{\mathrm{b}}$ \\
\hline$<300$ & $11(55.0)$ & $9(45.0)$ & $20(50.0)$ & \\
\hline$\geq 300$ & $2(10.0)$ & $18(90.0)$ & $20(50.0)$ & \\
\hline Total & $13(32.5)$ & $27(67.5)$ & $40(100.0)$ & \\
\hline
\end{tabular}

${ }^{a}$ The numbers (percentage contribution) are listed for each category. ${ }^{\mathrm{b}} \mathrm{McNemar}$ 's test. UIC, urinary iodine concentration.

presented with high UICs; consistently, the majority of PTC patients with high UIC ( $>80 \%)$ were from historically non-iodine deficient regions. This suggested an association between high UIC and iodine-excessive regions. Therefore, to a large extent, a high UIC may independently reflect excessive chronic iodine exposure in patients with PTC. Based on the aforementioned findings, ecology integrated assessment was used to investigate the association between chronic iodine exposure and the clinicopathological characteristics of patients with PTC. The results indicated that adaptive and high UIC values are associated with capsular invasion of carcinoma, but that only high UIC is significantly associated with extrathyroid metastasis. On the one hand, high iodine concentrations may promote PTC cell proliferation (represented by a higher iodine concentration) and manifest as higher rates of proliferation. On the other hand, this regularity only applies for iodine concentrations $\leq 1.0 \times 10^{-3} \mathrm{mmol} / 1$; beyond this boundary, the rate of proliferation gradually decreases (21). Importantly, the concentration of iodine in the normal human thyroid gland ranges between $1.0 \times 10^{-6}$ and $1.0 \times 10^{-5} \mathrm{mmol} / \mathrm{l}(21)$, which is below the aforementioned concentration. Therefore, for adaptive iodine levels and beyond, it was hypothesized that the higher the concentration of iodine in the thyroid gland (within a specified range, $1.0 \times 10^{-3} \mathrm{mmol} / \mathrm{l}$ ), the higher the rate of carcinoma cell proliferation; however, for extremely high iodine levels ( $\geq 1.0 \times 10^{-3} \mathrm{mmol} / 1$, for pathological thyroid gland), it was speculated in the present study that the proliferative rate may marginally decrease.

It should also be noted that the rate of proliferation usually reflects the potential for capsular invasion $(9,21)$. In this respect, it is apparent that both an adaptive and high UIC were equally significantly associated with capsular invasion, and the difference between the two was not statistically significant. Therefore, both adaptive and high UICs were concluded to enhance the potential for capsular invasion in patients with PTC. However, only high levels of iodine were able to upregulate the expression of vascular endothelial growth factor (VEGF)-A in W3 cells (21), MAPK in TPC-1 cells (22), and AKT in TFC (thyroid follicular cells) (23). AKT and MAPK are involved in the PI3K/AKT/mTOR and MAPK signaling pathways, respectively $(24,25)$; both activate downstream VEGF $(26,27)$, which is responsible for angiogenic activation and immune microenvironment disorders in carcinomas $(27,28)$, contributing to proliferation and metastasis (29-35). It was therefore hypothesized that only high concentrations of iodine can trigger the activation of the PI3K/AKT/mTOR and MAPK pathways and alter VEGF-mediated angiogenesis and immune reactions, thereby promoting the proliferation and metastasis of PTC. This may explain why only a high UIC was found to be significantly associated with capsular invasion and extrathyroid metastasis. Consequently, it was hypothesized that excessive chronic iodine exposure may promote capsular invasion and extrathyroid metastasis in patients with PTC.

Another innovation of the present study was the self-matching design and random selection of 40 patients, and the discovery that UIC grading does not differ significantly between the pre- and postoperative period, regardless of the presence of carcinomatous foci. This finding further excludes the possibility that a higher UIC may be attributed to the metabolism of carcinomatous foci. Therefore, it was concluded that a high UIC is indicative of excessive iodine exposure rather than the metabolic characteristics of the carcinoma per se, and this must be considered as a risk factor for pathogenic PTC.

The conclusions would have been more powerful if the study had included a larger prospective cohort from multiple centers (where high iodine exposure and PTC tumorigenesis were assessed over time), and more effort had been made to control the selective bias of this particular hospital (e.g., Berkson bias). Despite these limitations, however, convincing, manageable risk factors for PTC were identified. Furthermore, the aim of the study was to investigate the risk factors and their possible roles in patients with PTC, rather than to assess the iodine nutritional status of the general population. It is also not possible to exclude undiagnosed PTC cases within the general population and, therefore, in the present 
study, patients with thyroid nodules included those in the non-PTC group. Based on these findings, it is necessary to implement regional control strategies for iodine supplementation in Shandong, where the iodine-deficient, -adaptive and -excessive regions coexist. This may help to prevent invasion and metastasis in patients with PTC, particularly those with thyroid nodules.

Collectively, the results of the present study indicated that excessive chronic iodine exposure may promote capsular invasion and extrathyroid metastasis, and may be significantly associated with the risk of PTC.

\section{Acknowledgements}

The authors would like to thank Dr Chengjun Zhou, Dr Haitao Wang, Dr Xiaoying Wang and Dr Guoxin Teng, (Department of Pathology, The Second Hospital of Shandong University, Jinan, China) for their support with pathological diagnosis. The authors would also like to thank Dr Shouluan Ding and Chunchun Shao, (Evidence-Based Medicine Center, The Second Hospital of Shandong University, Jinan, China) for statistical advice.

\section{Funding}

This project was supported by the Research Development Fund of The Second Hospital of Shandong University (grant no. 11681808).

\section{Availability of materials and data}

All data generated or analyzed in the present study are available from the corresponding author upon reasonable request.

\section{Authors' contributions}

FH, JL and HJ designed the study. FH, WC, YZ, MG, JS, LS and LW collected and analysed the urine samples. FH, JX and QX analysed the data. ZY and HJ interpreted the data and provided academic guidance. $\mathrm{FH}$ drafted the manuscript, and JL, ZY and HJ made further revisions. All authors read and approved the final version of the manuscript.

\section{Ethics approval and consent to participate}

The present study was approved by the Research Ethics Committee of The Second Hospital of Shandong University; ethics approval no.: [KYLL-2019(KJ)P-0084]. All patients were informed of the purpose of the study and volunteered to participate.

\section{Patient consent for publication}

Not applicable.

\section{Competing interests}

The authors declare that they have no competing interests.

\section{References}

1. Sui C, Liang N, Du R, He Q, Zhang D, Li F, Fu Y, Dionigi G and Sun H: Time trend analysis of thyroid cancer surgery in China: Single institutional database analysis of 15,000 patients. Endocrine 68: 617-628, 2020

2. Brito JP, Gionfriddo MR, Al Nofal A, Boehmer KR, Leppin AL, Reading C, Callstrom M, Elraiyah TA, Prokop LJ, Stan MN, et al: The accuracy of thyroid nodule ultrasound to predict thyroid cancer: Systematic review and meta-analysis. J Clin Endocrinol Metab 99: 1253-1263, 2014.

3. Kitahara CM and Sosa JA: The changing incidence of thyroid cancer. Nat Rev Endocrinol 12: 646-653, 2016.

4. Lee JH, Song RY, Yi JW, Yu HW, Kwon H, Kim SJ, Chai YJ, Choi JY, Moon JH, Lee KE, et al: Case-control study of papillary thyroid carcinoma on urinary and dietary iodine status in South Korea. World J Surg 42: 1424-1431, 2018.

5. Zhou Z, Zhang J, Jiang F, Xie Y, Zhang X and Jiang L: Higher urinary bisphenol a concentration and excessive iodine intake are associated with nodular goiter and papillary thyroid carcinoma. Biosci Rep 37: BSR20170678, 2017.

6. Zhang L, Fang C, Liu L, Liu X, Fan S, Li J, Zhao Y, Ni S, Liu S and $\mathrm{Wu} \mathrm{Y}$ : A case-control study of urinary levels of iodine, perchlorate and thiocyanate and risk of papillary thyroid cancer. Environ Int 120: 388-393, 2018.

7. Zhao $\mathrm{H}, \mathrm{Li} \mathrm{H}$ and Huang T: High urinary iodine, thyroid autoantibodies, and thyroid-stimulating hormone for papillary thyroid cancer risk. Biol Trace Elem Res 184: 317-324, 2018.

8. Zhao H, Li H and Huang T: High iodine intake and central lymph node metastasis risk of papillary thyroid cancer. J Trace Elem Med Biol 53: 16-21, 2019.

9. Wang F, Wang Y, Wang L, Wang X, Sun C, Xing M and Zhao W: Strong association of high urinary iodine with thyroid nodule and papillary thyroid cancer. Tumour Biol 35: 11375-11379, 2014.

10. Kim HJ, Park HK, Byun DW, Suh K, Yoo MH, Min YK, Kim SW and Chung JH: Iodine intake as a risk factor for BRAF mutations in papillary thyroid cancer patients from an iodine-replete area. Eur J Nutr 57: 809-815, 2018

11. Vuong HG, Kondo T, Oishi N, Nakazawa T, Mochizuki K, Inoue T, Tahara I, Kasai K, Hirokawa M, Tran TM and Katoh R: Genetic alterations of differentiated thyroid carcinoma in iodine-rich and iodine-deficient countries. Cancer Med 5: 1883-1889, 2016.

12. Lv C, Yang Y, Jiang L, Gao L, Rong S, Darko GM, Jiang W, Gao Y and Sun D: Association between chronic exposure to different water iodine and thyroid cancer: A retrospective study from 1995 to 2014. Sci Total Environ 609: 735-741, 2017.

13. Bogdanova TI, Saenko VA, Hirokawa M, Ito M, Zurnadzhy LY, Hayashi T, Rogounovitch TI, Miyauchi A, Tronko MD and Yamashita S: Comparative histopathological analysis of sporadic pediatric papillary thyroid carcinoma from Japan and Ukraine. Endocr J 64: 977-993, 2017.

14. Santos JE, Freitas M, Fonseca CP, Castilho P, Carreira IM, Rombeau JL and Branco MC: Iodine deficiency a persisting problem: Assessment of iodine nutrition and evaluation of thyroid nodular pathology in Portugal. J Endocrinol Invest 40: 185-191, 2017.

15. Zhang YL, Li P, Liu ZY, Yi JP, Chen Y, Zhang M and Lin Q: Does relatively low iodine intake contribute to thyroid cancer? An ecological comparison of epidemiology. Medicine (Baltimore) 98: e17539, 2019.

16. World Health Organization, UNICEF, ICCIDD: Assessment of iodine deficiency disorders and monitoring their elimination, a guide for programme managers Third edition (updated 1st September 2008), pp 32-33..

17. Gao J, Zhang ZJ, Wang ZL, Bian JC, Wang JB, Jiang W, Wang XM and Jiang QW: Spatial distribution characteristics and influencing factors of iodine in drinking water in Shandong Province between year 2008 and 2010. Zhonghua Yu Fang Yi Xue Za Zhi 47: 18-22, 2013 (In Chinese).

18. Horvath E, Majlis S, Rossi R, Franco C, Niedmann JP, Castro A and Dominguez M: An ultrasonogram reporting system for thyroid nodules stratifying cancer risk for clinical management. J Clin Endocrinol Metab 94: 1748-1751, 2009.

19. Zimmermann MB and Boelaert K: Iodine deficiency and thyroid disorders. Lancet Diabetes Endocrinol 3: 286-295, 2015.

20. Mitro SD, Rozek LS, Vatanasapt P, Suwanrungruang K, Chitapanarux I, Srisukho S, Sriplung H and Meza R: Iodine deficiency and thyroid cancer trends in three regions of Thailand, 1990-2009. Cancer Epidemiol 43: 92-99, 2016. 
21. Xiang J, Wang X, Wang Z, Wu Y, Li D, Shen Q, Sun T, Guan Q and Wang Y: Effect of different iodine concentrations on well-differentiated thyroid cancer cell behavior and its inner mechanism. Cell Biochem Biophys 71: 299-305, 2015.

22. Wang J, Yang H, Si Y, Hu D, Yu Y, Zhang Y, Gao M and Zhang H: Iodine promotes tumorigenesis of thyroid cancer by suppressing mir-422a and up-regulating MAPK1. Cell Physiol Biochem 43: 1325-1336, 2017.

23. Xu C, Wu F, Mao C, Wang X, Zheng T, Bu L, Mou X, Zhou Y, Yuan G, Wang S and Xiao Y: Excess iodine promotes apoptosis of thyroid follicular epithelial cells by inducing autophagy suppression and is associated with Hashimoto thyroiditis disease. J Autoimmun 75: 50-57, 2016.

24. Huang F, Sun Y, Gao H, Wu H and Wang Z: Carbon disulfide induces embryo loss by perturbing the expression of the mTOR signalling pathway in uterine tissue in mice. Chem Biol Interact 300: 8-17, 2019.

25. Zhao X, Hou P, Xin H, Zhang Y, Zhou A, Lai C and Xie J: A glucogalactomanan polysaccharide isolated from Agaricus bisporus causes an inflammatory response via the ERK/MAPK and IKB/NFKB pathways in macrophages. Int J Biol Macromol 151: 1067-1073, 2020

26. Geng J, Li X, Zhou Z, Wu CL, Dai M and Bai X: EZH2 promotes tumor progression via regulating VEGF-A/AKT signaling in non-small cell lung cancer. Cancer Lett 359: 275-287, 2015.

27. Tsai HC, Cheng SP, Han CK, Huang YL, Wang SW, Lee JJ, Lai CT, Fong YC and Tang CH: Resistin enhances angiogenesis in osteosarcoma via the MAPK signaling pathway. Aging (Albany NY) 11: 9767-9777, 2019.

28. Wheeler KC, Jena MK, Pradhan BS, Nayak N, Das S, Hsu CD, Wheeler DS, Chen K and Nayak NR: VEGF may contribute to macrophage recruitment and M2 polarization in the decidua. PLoS One 13: e0191040, 2018.
29. Song J, Qiu W, Deng X, Qiu Z, Fan Y and Yang Z: A somatic mutation of RasGRP3 decreases $\mathrm{Na}^{+} / \mathrm{I}^{-}$symporter expression in metastases of radioactive iodine-refractory thyroid cancer by stimulating the Akt signaling pathway. Am J Cancer Res 8: 1847-1855, 2018

30. Subarnbhesaj A, Miyauchi M, Chanbora C, Mikuriya A, Nguyen PT, Furusho H, Ayuningtyas NF, Fujita M, Toratani S, Takechi M, et al: Roles of VEGF-Flt-1 signaling in malignant behaviors of oral squamous cell carcinoma. PLoS One 12: e0187092, 2017.

31. Li Y, Sun R, Zou J, Ying Y and Luo Z: Dual roles of the AMP-activated protein kinase pathway in angiogenesis. Cells 8: $752,2019$.

32. Shakya G, Balasubramanian S, Hoda M and Rajagopalan R: Inhibition of metastasis and angiogenesis in Hep-2 cells by wheatgrass extract-an in vitro and in silico approach. Toxicol Mech Methods 28: 205-218, 2018.

33. Welsh SJ, Rizos H, Scolyer RA and Long GV: Resistance to combination BRAF and MEK inhibition in metastatic melanoma: Where to next? Eur J Cancer 62: 76-85, 2016.

34. Hegde PS, Wallin JJ and Mancao C: Predictive markers of anti-VEGF and emerging role of angiogenesis inhibitors as immunotherapeutics. Semin Cancer Biol 52: 117-124, 2018.

35. Turkowski K, Brandenburg S, Mueller A, Kremenetskaia I, Bungert AD, Blank A, Felsenstein M and Vajkoczy P: VEGF as a modulator of the innate immune response in glioblastoma. Glia 66: 161-174, 2018.

This work is licensed under a Creative Commons Attribution-NonCommercial-NoDerivatives 4.0 International (CC BY-NC-ND 4.0) License. 